\title{
Bilingual and Monolingual Parents' Beliefs About Bilingualism and Bilingual Education
}

\author{
Miaojing Zhang
}

\author{
Miami University \\ Email: zhangmiaojing2018@163.com
}

\begin{abstract}
Whether children should be encouraged to acquire two languages at an early stage is a controversial topic. There are therefore huge individual differences in how parents may reason about bilingual education, and this can greatly impact their parental practices on bilingualism-related topics. To understand how parents think about bilingualism and bilingual education, the current study surveyed $N=178$ parents from Prolific on their views about early bilingual education. The results show that all parents have a positive attitude towards early bilingual learning. However, there are also some differences between monolingual and bilingual parents. Specifically, bilingual parents are less likely to think that early bilingual learning is easy to cause confusion in grammar, reading, vocabulary and accent; whereas monolingual parents are less agreeing with that early learning second language promotes cognitive development and information processing efficiency. In addition, bilinguals generally were less likely to believe that bilingual learning is prone to stress and fatigue. But at the same time, monolinguals tended to believe that bilingual learning helps children understand their self-identity more so than bilingual parents. This study contributes to the understanding on parents' views about child early bilingual education. Future directions and limitations are discussed.
\end{abstract}

Keywords: Bilingual, Monolingual, Parents' views, Early bilingual education.

\section{INTRODUCTION}

Whether early bilingualism benefits children is a heated but controversial topic: people holding the bilingual advantage account believe that early bilingual exposure brings children cognitive advantages and benefits their language development; however, some other people believe that learning another language early on may delay the development of children's first language. Importantly, how parents think of early bilingualism influences their choice of children's language education. Nonetheless, few studies exist on parents' views about early bilingual education, and how it might vary by parents' own bilingualism status. To address this gap, the current research aimed to explore how monolingual and bilingual parents think of early bilingualism and bilingual education.

Research on the role of early bilingualism often yields mixed results. Some studies found that bilingual learning is beneficial to children's intellectual and cognitive development. For example, Bialystok [1] found that bilingual children reacted faster in attention switching tasks than monolingual children with equivalent vocabulary, family background and working memory. However, Morton [2] found that for bilingual and monolingual children with matched language skills and SES, they also performed similarly in tasks of cognitive control. Moreover, in some bilingual children growing up in the US, they may even show insufficient English proficiency. For instance, Hoff's [3] research showed that children in the bilingual immigrant families are exposed to both a mother tongue and second language from birth, and their proficiency in both languages is quite low by the time they reach school age. Moreover, in his other study [4], by assessing the language skills of children aged 30-60 months, the vocabulary of monolingual children aged 3-5 years was significantly higher than that of Spanish British Bilingual immigrant children. At each age group, monolingual children were asked to take the English expressive one-word picture vocabulary test (EOWPVT); Bilingual children received the Spanish bilingual version of EOWPVT in Spanish and English in a balanced order on different days, and then the scores of the two languages were summed and analyzed. In addition, the frequency and the specific situation of children's monolingual or bilingual use at home are assessed through reports and feedback from parents. The results show that bilingual children may lag 
behind monolingual children for half a year or even a year in normal English language development.

Despite the bilingual debate in the research literature, little is known on how the general public, especially children's parents, thinks about bilingualism and bilingual education. One study looked at views of child health nurses on bilingual development [5]. The association between the simplicity of screening result variables and nurses' perceptions of language development speed, screening result interpretation, and confidence in bilingual children's own knowledge during the screening was investigated in this study. Then the result shows that more than 82 percent of nurses believe that bilingual children's language development is slower than that of monolingual children. In addition, previous interviews [6] also found that although some parents felt that bilingual learning has certain advantages, but at the same time they were worried that early bilingualism may damage their children's English level and affect their language proficiency.

How parents view early bilingualism may also vary as a function of their own bilingual status. For bilingual parents, they have the experience of a second language learning, so they may realize the importance and practicability of second language. Under such conditions, they may a high degree of support for bilingual learning. For monolingual parents, not interested. Alternatively, since bilingual education is popular in many countries, they may thus be interested in sending their children to a bilingual school.

The current study aims to explore the effects of bilingualism on children's academic performance, psychosocial and cognitive development, as well as parents' views on early second language learning. We hypothesize that, for parents' views on bilingual learning, parents think bilingualism is generally positive, and bilingual parents prefer to expose their children to bilingual education; For parent expectation, the higher the expected degree, the more likely participants emphasize academic achievement at school; For the psychosocial and cognitive influence of bilingualism, Bilinguals are more likely to think that bilingual learning has a positive impact, while monolinguals are more likely to think that bilingual learning has little impact on these two aspects.

\section{METHOD}

\subsection{Participants}

Participants are $N=205$ adults recruited from Prolific, with an average age $\left(M_{\text {age }}=36.71, S D_{\text {age }}=6.54\right.$, , , half identified themselves as bilinguals $(N=102)$ and half monolinguals $(N=103)$. There was no age difference between the two groups. They were paid $\$ 4$ to complete a Qualtrics survey. The questionnaire was open to adult parents aged 25-50 years old and have at least one child under 18 years old. The questionnaire was conducted in English. Among all participants, $9.6 \%$ are in the US, 36.5\% were from the UK, $12.4 \%$ were from Mexico, $5.1 \%$ from Australia, and the rest of them $(36.4 \%)$ were from other countries.

There were three attention-check items (for example, "Please select 'somewhat agree' for this item"). $N=27$ responses were removed because they failed to pass at least one of the attention-check items. The final sample consisted of 178 adults $\left(M_{\text {age }}=36.74, S D_{\text {age }}=6.55\right)$, and $55 \%$ were female. Fifty-one percent $(N=91)$ were bilingual, among whom eighty-nine percent $(N=81)$ said they had learned and mastered a second language before the age of 18 , and fifty-five percent $(N=50)$ said they had learned and mastered a second language before the age of 7 .

\subsection{Procedure}

Participants completed a 52-item questionnaire which is divided into three parts. The first part asked about participants' demographic information (i.e., gender, age, educational level, nationality, etc.) and their language backgrounds. The second part included 26 items probing participants' attitudes on bilingual acquisition. The last part asked about parents' expectations of their children's language education.

\subsection{Measure}

\subsubsection{Language Background}

First, participants were asked to answer which country they grew up in. Then they were asked whether they ever lived in other country(s) for more than a year. If yes, they were then asked to specify the country(s). For bilinguals, additional questions were added to probe their dual-language learning experiences. Specifically, they were asked to indicate the languages they speak, and the age of acquisition for each language.

\subsubsection{Beliefs about influences of early bilingual acquisition}

Parents' beliefs about the bilingual acquisition were measured through three subscales which probed specific beliefs in prenatal bilingual education, early bilingualism, and psychosocial influence aspects. All items were answered on a six-point Likert scale $(1=$ strongly disagree, 6 = strongly agree).

\subsubsection{Prenatal bilingual education}

There were two questions about whether prenatal education has positive impacts on children's future language development to ask participants to rate that how they think about bilingualism and language acquisition. For example, "Prenatal education (i.e. reading or playing 
music to the fetus before birth) is beneficial for babies' language development in the future".

\subsubsection{Early bilingualism}

The questionnaire also uses 14 more questions to explore people's views on simultaneous bilingual learners before 3 years old and their attitude toward simultaneous bilingual children. They were divided into three sub-scales. The first sub-scale focuses on the relationship between first and second languages. So this part contains various good or bad factors that the second language learning will affect the development of the first language like it causes confusion in the use of grammar rules, vocabulary and children's accent. For example, "Simultaneous bilinguals causes confusion in future (word) reading (e.g., for a French-English bilingual child, when s/he tries to read the English word "example", she may read it as the French "exemple")". Then, in the second sub-scale, exploring the influence of bilingual learning on cognition is the most important. This part mainly asks whether bilingual learning has a positive or negative impact on children's cognition. For example, "Simultaneous bilinguals learning makes children process information faster." The next sub-scale is about the prediction of children's future academic performance development. For example, "Their early dual language learning experience gives them an advance in school reading achievement", etc.

\subsubsection{Psychosocial influence}

There were four questions about participants' attitudes towards the psychological and cognitive development of children learning bilingualism. For instance, "It helps children to understand their selfidentity, such as racial, ethnic or religions identities." Then participants were asked to rate the extent they agree with each statement on a six-point scale.

\subsubsection{Parental Educational Expectation}

Firstly, there is one question about the interaction between language environment and innate language talent, letting participants judge from the perspective of parents whether they think language environment is more important or language talent is for children to learn a second language.
As for the parent educational expectation itself, the questions participants need to answer are not limited to "language". It includes topics related to other kinds of expectations, such as children's academic performance, children's future development and so on. For example, the highest education that the parent wants their child to get, whether you want your child to study abroad, whether you want your child to go abroad for employment, etc. In addition, participants finish a Rank order question, which proposes some skills that children may learn in school to deal with people and use in their life, then participants need to judge the importance of these skills and rank them from most valuable to the least valuable in their perspective. These skills are academic achievements, ability to stay disciplined, positive impression from teachers, sense of morality (or moral standards), emotional intelligence, ability to work in a team, leadership skills, ability to express him/herself, popularity among their peers respectively. In this way, it is easy to see which aspect of children's development is more valued by parents. At the same time, it is convenient to judge the differences between bilingual and monolingual parents' expectations of children through their answers.

\section{RESULT}

Table 1 displays the descriptive statistics (Means and SDs) and group differences of bilingual and monolingual parents' ratings of all the early bilingualism attitude items. In general, both bilinguals and monolinguals more agree with the narration of simultaneously languages more beneficial, while they are more neutral about the statement that children should learn the first language well before the introduction of the second language. Interestingly, on the issue of "learning two languages at the same time is more beneficial than learning one language at a time", there is a significant difference between bilinguals and monolinguals $(p=.017)$. In the statements that prenatal education, such as reading aloud or playing music to the fetus before birth, is beneficial to and can accelerate the future language development of the baby, the support of bilinguals is slightly higher than that of monolinguals. However, in the response to the statement that children's first language should be welllearned before a second language is introduced, monolinguals have a slightly higher degree of support than bilinguals.

Table 1. Prenatal Education Descriptive Statistics.

\begin{tabular}{|l|l|l|l|}
\hline Prenatal Education Wording & Bilinguals M(SD) & Monolinguals M(SD) & $p$ value \\
\hline $\begin{array}{l}\text { Prenatal education (i.e. reading or playing music to } \\
\text { the fetus before birth) is beneficial for babies' } \\
\text { language development in the future. }\end{array}$ & $4.34(1.26)$ & $4.25(1.11)$ & .623 \\
\hline
\end{tabular}




\begin{tabular}{|l|l|l|l|}
\hline $\begin{array}{l}\text { Exposing children to prenatal education (i.e. } \\
\text { reading or playing music to the fetus before birth) } \\
\text { accelerates children's language development. }\end{array}$ & $4.36(1.19)$ & $4.17(1.06)$ & .262 \\
\hline $\begin{array}{l}\text { It is beneficial for children to learn two languages } \\
\text { simultaneously than learning one at a time. }\end{array}$ & $4.87(1.19)$ & $4.44(1.21)$ & $.017^{*}$ \\
\hline $\begin{array}{l}\text { For a child, their first language should be well- } \\
\text { learned before a second language is introduced. }\end{array}$ & $3.14(1.61)$ & $3.39(1.65)$ & .312 \\
\hline
\end{tabular}

Note: $*$ indicates that $\mathrm{p}$-value less than $0.05, * *$ indicates

that $p$-value less than 0.01 .

Table 2 illustrates people's views on bilingual simultaneous learners. It shows the mean and standard deviation of the monolingual and bilingual agreement for each statement, and the correlation between them. Critically, monolinguals are more likely to think that simultaneous bilingual learning will easily confuse grammar, reading, vocabulary and accent. Especially in the aspect of accent confusion, there is a significant difference between bilinguals and monolinguals ( $p$ $=.039$ ). In addition, as far as promoting cognitive development is concerned, bilinguals have a higher agreement with the statements that simultaneous languages promote cognitive development than monolinguals. From the overall average value of the subscale, there is a significant difference between bilinguals and monolinguals $(p=.015)$. Especially for processing information faster, bilinguals have higher approval than monolinguals $(p<.001)$. Meanwhile, as expected, bilinguals have more positive support for the development of academic achievement. Bilingual and monolingual views on mathematics advantage are statistically significant ( $p=.01)$. What's more surprising is that for the viewpoint of giving an advantage in future academic achievement overall, there is a highly statistically significant degree of agreement between bilinguals and monolinguals $(p=.01)$.

Table 2. Attitude toward Simultaneous Bilingual Learners.

\begin{tabular}{|c|c|c|c|c|}
\hline Survey & Type & Bilinguals $M(S D)$ & Monolinguals $M(S D)$ & $p$ value \\
\hline \multirow{5}{*}{$\begin{array}{l}\text { Language } \\
\text { Disadvantage }\end{array}$} & Causes grammar confusion & $3.02(1.39)$ & $3.23(1.15)$ & .279 \\
\hline & Causes reading confusion & $2.76(1.27)$ & $2.99(1.08)$ & .195 \\
\hline & Causes vocabulary confusion & $2.84(1.24)$ & $3.05(1.22)$ & .255 \\
\hline & Causes accents confusion & $3.03(1.40)$ & 2.61(1.31) & $.039 *$ \\
\hline & Average Language Disadvantage & $2.91(1.13)$ & $2.97(0.98)$ & .724 \\
\hline \multirow[t]{7}{*}{$\begin{array}{l}\text { Cognitive } \\
\text { Advantage }\end{array}$} & $\begin{array}{l}\text { Strengthens children's ability to } \\
\text { stay focused }\end{array}$ & $4.31(1.15)$ & $4.09(1.14)$ & .210 \\
\hline & Makes children easily distracted & $2.15(1.06)$ & $2.37(1.07)$ & .182 \\
\hline & $\begin{array}{l}\text { Gives children cognitive } \\
\text { advantages }\end{array}$ & $4.89(1.02)$ & $4.69(0.81)$ & .149 \\
\hline & $\begin{array}{l}\text { Makes children process } \\
\text { information faster }\end{array}$ & $4.73(0.99)$ & 4.16(1) & $<.001^{\star \star}$ \\
\hline & $\begin{array}{l}\text { Makes children remember more } \\
\text { things in a short time }\end{array}$ & $4.32(1)$ & 4.07(0.98) & .093 \\
\hline & makes children remember faster & $4.37(1.10)$ & $4.10(0.95)$ & .082 \\
\hline & Average Cognitive Advantage & $4.57(0.8)$ & $4.29(0.73)$ & $.015^{\star}$ \\
\hline \multirow[t]{2}{*}{ Achievement } & $\begin{array}{l}\text { Advantage in school reading } \\
\text { achievement }\end{array}$ & $4.7(1.18)$ & $4.43(0.88)$ & .078 \\
\hline & $\begin{array}{l}\text { Advantage in future mathematics } \\
\text { learning }\end{array}$ & $4(1.25)$ & $3.54(1.11)$ & $.010^{*}$ \\
\hline
\end{tabular}




\begin{tabular}{|l|l|l|l|l|}
\hline & $\begin{array}{l}\text { Advantage in future academic } \\
\text { achievement overall }\end{array}$ & $5.06(1.16)$ & $4.62(1.05)$ & $.009^{\star \star}$ \\
\cline { 2 - 5 } & Average Achievement & $4.57(1.01)$ & $4.2(0.78)$ & $.006^{\star \star}$ \\
\hline
\end{tabular}

Note: $*$ indicates that $\mathrm{p}$-value less than $0.05, * *$ indicates that $p$-value less than 0

Table 3 explains people's attitudes toward simultaneous bilingual children. As we can see, monolinguals generally believe that bilingual learning is prone to stress and fatigue. But at the same time, compared with bilinguals, monolinguals tend to think that simultaneous bilingual learning helps children to understand their self-identity. There is no significant difference in this sub-scale.

Table 3. Attitudes towards Simultaneous Bilingual Children.

\begin{tabular}{|l|l|l|}
\hline Type & Bilinguals $M(S D)$ & Monolinguals M(SD) \\
\hline It helps children to understand their self-identity & $4.2(1.34)$ & $4.44(1.04)$ \\
\hline It puts children under a lot of mental burden & $2.59(1.38)$ & $2.61(1.13)$ \\
\hline It puts children under a lot of psychological pressure & $2.46(1.33)$ & $2.63(1.14)$ \\
\hline It makes children feel easily exhausted & $2.56(1.28)$ & $2.66(1.26)$ \\
\hline
\end{tabular}

Table 4 indicates, as parents, the expectation of children's future development. It can be seen from the table that both bilinguals and monolinguals value the development of children's emotional intelligence most. Both of them pay the least attention to the popularity of their children among their peers. There is a significant difference $(p=.036)$. Interestingly, there are more monolinguals than bilinguals who think that teachers' positive impression on children is very important, and there is a highly significant difference $(p<.001)$. More bilinguals think that children's leadership ability is important than monolinguals, and there is a highly significant difference in the data $(p<.001)$. In other skills about children's development, there is no significant difference between bilinguals and monolinguals. Statistics show that more bilinguals think the skills of academic achievement, discipline, emotional intelligence development and group cooperation are important than monolinguals, while more monolinguals think the sense of morality and self-expression are important than bilinguals.

Table 4. Parents' Expectation Ranking.

\begin{tabular}{|l|l|l|l|l|}
\hline Survey & Type & Bilinguals $M(S D)$ & Monolinguals M(SD) & $p$ value \\
\hline \multirow{4}{*}{$\begin{array}{l}\text { The skills they } \\
\text { value most about } \\
\text { their children }\end{array}$} & Academic achievements & $3.59(2.18)$ & $3.69(2.32)$ & .776 \\
\cline { 2 - 5 } & Ability to stay disciplined & $4.16(2.18)$ & $4.56(2.16)$ & .223 \\
\cline { 2 - 5 } & $\begin{array}{l}\text { Positive impression from } \\
\text { teachers }\end{array}$ & $7.2(1.69)$ & $6.2(2.08)$ & $<.001^{\star \star}$ \\
\cline { 2 - 5 } & Sense of morality & $3.99(2.31)$ & $3.52(2.1)$ & .156 \\
\cline { 2 - 5 } & Emotional intelligence & $3.29(2)$ & $3.49(2.19)$ & .508 \\
\cline { 2 - 5 } & Ability to work in a team & $5.41(1.83)$ & $5.67(1.99)$ & .364 \\
\cline { 2 - 5 } & Leadership skills & $4.99(1.96)$ & $6.25(2.29)$ & $<.001^{\star \star}$ \\
\cline { 2 - 5 } & Ability to express him/herself & $3.98(2.41)$ & $3.69(2.18)$ & .404 \\
\cline { 2 - 5 } & Popularity among their peers & $8.4(1.22)$ & $7.93(1.69)$ & $.036^{\star}$ \\
\hline
\end{tabular}

Note: * indicates that $\mathrm{p}$-value less than $0.05, * *$ indicates that $\mathrm{p}$-value less than 0.01 


\section{DISCUSSION}

From the results of the data analysis, monolingual parents and bilingual parents generally believe that bilingual learning has certain advantages. However, they differ in some specific views. As for table 2, bilingual parents tend to hold a more positive view of bilingual education. For example, they are more convinced that bilingual learning makes children receive and process information faster, and that bilingual learning will give children the advantages of cognitive development and academic achievement. However, in terms of accent confusion in language learning, bilingual parents have the opposite attitude. They more recognize that bilingual learning has a negative impact on children's accent confusion. In addition, as for table 4, bilingual parents and monolingual parents also have some differences in their views on expectations for their children. For example, monolingual parents pay more attention to the development of their children's interpersonal relationships and teachers' evaluation of their children, while bilingual parents pay more attention to the improvement and development of their children's leadership.

Bilingual parents' evaluation of bilingual learning is relatively more positive. One of the reasons may be that they have experienced the process and benefit of learning a second language, so they have a deeper understanding of these advantages and disadvantages. They look at children's bilingual learning from the perspective of the first person. However, monolingual parents have not been exposed to the second language, so their evaluation and views are more based on the others' description or the surface phenomena observed by themselves. There are no specific examples and experiences to support them to experience the advantages and disadvantages of bilingual learning. Therefore, their views on bilingual learning are more divided and mixed.

\section{CONCLUSION}

In general, this study provides a reference for the development of children's bilingual learning. Most previous studies have focused on the difference between bilingual learning and monolingual learning, and few studies are about parents' views on children's bilingual learning. Therefore, this study makes an initial attempt to fill the gap in this area. Later research can also be based on this research to further explore the advantages and disadvantages of bilingual learning and monolingual learning. At the same time, the study also has a positive impact on bilingual education in the future. This has helped publicize the existence and significance of bilingual learning, promoted the public to understand the views of parents on bilingual learning, and attracted more parents' attention to bilingual education.
However, there are also some limitations in the process of this study. First, the sample size is not large enough. Due to the limited time and during the COVID19 epidemic, we can only collect participants' answers through the online questionnaire. Also, the samples are too scattered. We collected the views of bilinguals and monolinguals in various countries on bilingual learning. If we only focus on one country for investigation and statistics, the data and results will be more reliable and credible. In addition, since the study covers the answers of people in different countries, different countries also have different policies. Some countries may stipulate that children must start learning a second language or English at a specific age, while some countries have no specific requirements in this regard. Such a social background is beyond our control. Finally, our research object is parents, but parents of children of different ages will have different attitudes towards their children's education. For example, for children who are still in infancy, their parents may think it necessary to learn a second language, because the child is still young and has time to learn any new knowledge. However, parents with children around the age of 17 or 18 may think that learning a second language is no longer important, and they will not be interested in early learning a second language. At the same time, parents of different ages also have different considerations and perspectives on education. For example, parents in their thirties will keep up with the development of society, be interested in trying new things, and be willing to guide their children to learn a second language; Parents in their 40s and 50s will look at things with an ordinary mind, do not pursue fame and wealth, and are not willing to put too much pressure on their children. These will lead to different results, and we have no control.

\section{REFERENCES}

[1]. Bialystok, E. (1999). Cognitive Complexity and Attentional Control in the Bilingual Mind. Children Development. Volume 70, Number 3, Pages 636-644.

[2]. Morton, J. B., \& Harper, S. N. (2007). What did Simon say? Revisiting the bilingual advantage. Developmental Science, 10(6), 719-726.

[3]. Hoff, E. (2018). Bilingual development in children of immigrant families. Child development perspectives, 12(2), 80-86.

[4]. Hoff, E., \& Ribot, K. M. (2017). Language growth in English monolingual and SpanishEnglish bilingual children from 2.5 to 5 years. The Journal of pediatrics, 190, 241-245.

[5]. Nayeb, L., Wallby, T., Westerlund, M., Salameh, E. K., \& Sarkadi, A. (2015). Child healthcare nurses believe that bilingual children show slower language development, simplify screening 
procedures and delay referrals. Acta Paediatrica, 104(2), 198-205.

[6]. Piller, I., \& Gerber, L. (2018). Family language policy between the bilingual advantage and the monolingual mindset. International Journal of Bilingual Education and Bilingualism. 